disease. Technologic advancements are often developed in the adult population first. The unfortunate reality is that the development of novel devices and technology for children is limited by the relatively small volume of pediatric cardiac patients. Creative applications of these advances in adult medicine may prove to be the best source for innovative treatment strategies for challenging pediatric cardiac problems in the future.

\section{References}

1. Moysich A, Kerst G, Akintürk H, Schranz D. Transapical valve-in-valve implantation to treat a regurgitant mitral bioprosthesis in a child with failing Fontan circulation. J Thorac Cardiovasc Surg. 2015;150:e23-5.

2. Quiñonez LG, Breitbart R, Tworetsky W, Lock JE, Marshall AC, Emani SM. Stented bovine jugular vein graft (Melody valve) for surgical mitral valve replacement in infants and children. J Thorac Cardiovasc Surg. 2014;148: 1443-9.

3. Wong DJ, Iyengar AJ, Wheaton GR, Ramsay JM, Grigg LE, Horton S, et al. Longterm outcomes after atrioventricular valve operations in patients undergoing single-ventricle palliation. Ann Thorac Surg. 2012;94:606-13; discussion 613.

\title{
First surgical implantation of a sutureless valve in the pulmonary outflow tract
}

\author{
Gilles Touati, MD, Joseph Nader, MD, Franck Levy, MD, and Thierry Caus, MD, PhD, Amiens, France
}

See related commentary on pages e27-8.

Since 2008, sutureless valves have been used frequently in adult cardiac surgery for aortic valve replacement in severe aortic stenosis because of their efficiency of implantation and reduced crossclamp times. ${ }^{1,2}$ We report the first surgical implantation of a sutureless valve in the pulmonary position.

\section{CLINICAL SUMMARY}

An 82-year-old man was admitted with increased dyspnea caused by a mitral regurgitation associated with an aortic stenosis. Transthoracic and transesophageal echocardiography found a nondilated left ventricle with normal ejection fraction $(65 \%)$, associated with a surgical aortic stenosis, and a grade III mitral regurgitation due to anterior leaflet prolapse (A2), associated with moderate pulmonary hypertension (systolic pulmonary artery pressure $40 \mathrm{~mm} \mathrm{Hg}$ ). A grade II pulmonary valve insufficiency due to a dilated pulmonary annulus $(45 \mathrm{~mm})$ was also detected without right ventricle enlargement. ${ }^{3}$

The local heart team decided on a double aortic and mitral valve treatment in view of the patient's age and the complexity of the procedure. A Perceval L (Sorin, Milan,

\footnotetext{
From the Department of Cardiac Surgery, Amiens Picardy University Hospital, Amiens, France.

Disclosures: Authors have nothing to disclose with regard to commercial support.

Received for publication March 23, 2015; revisions received May 6, 2015; accepted for publication May 9, 2015; available ahead of print June 3, 2015.

Address for reprints: Joseph Nader, MD, Department of Cardiac Surgery, Amiens

Picardy University Hospital, Amiens, France (E-mail: nader_joe@ hotmail.com).

J Thorac Cardiovasc Surg 2015;150:e26-7

$0022-5223 / \$ 36.00$

Copyright (C) 2015 by The American Association for Thoracic Surgery

http://dx.doi.org/10.1016/j.jtcvs.2015.05.032
}

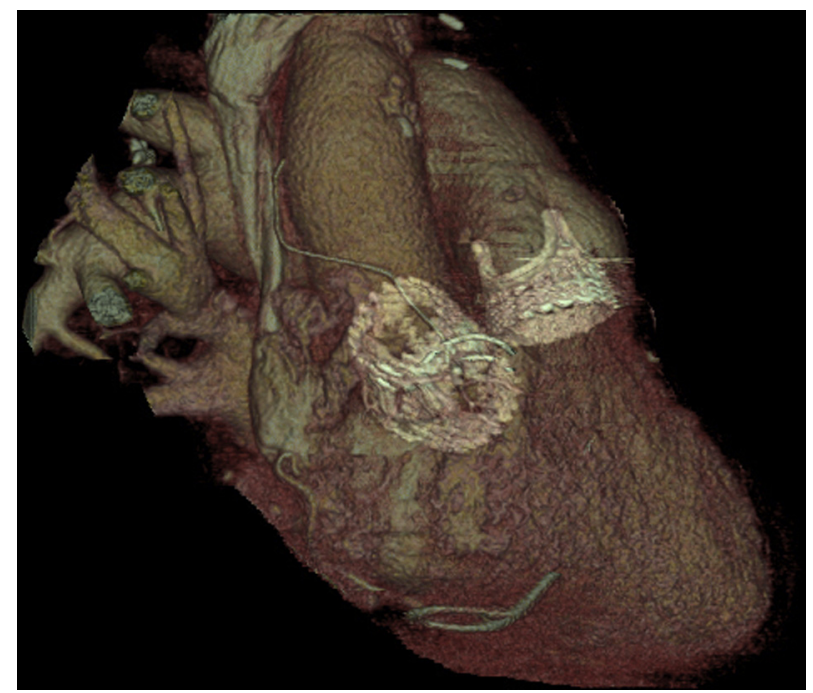

FIGURE 1. Post-operative 3D computed tomography scan showing the double sutureless valves in aortic and pulmonary position.

Italy) sutureless bioprosthesis was implanted in the aortic root with a concomitant mitral valvuloplasty by inserting 3 neochordae from the prolapsed anterior leaflet to the papillary muscles. Perioperative transesophageal echocardiography showed no paravalvular aortic leak or mitral regurgitation. The pulmonary insufficiency was moderate compared with the preoperative status.

In the intensive care unit, on the second postoperative day, a complete atrioventricular block appeared. Transthoracic echocardiography, supported by transesophageal echocardiography, identified an increased pulmonary regurgitation (grade IV), almost certainly due to a pulmonary hypertension crisis associated with a double stress event: patient awakening and 
right ventricle overfilling, without any anatomic modification of the pulmonary annulus (due to the sutureless aortic valve).

The patient then underwent a second operation using a 46-minute cardiopulmonary bypass without an aortic crossclamp. A 27-mm sutureless Carpentier Edwards INTUITY Elite valve (Edwards Lifesciences, Irvine, Calif) was implanted in the pulmonary annulus via a vertical pulmonary artery incision (Figure 1).

We modified the implantation technique by putting 3 stitches in the nadir of each cusp as recommended for the standard aortic valve replacement, adding another 3 stitches on the commissures to ensure a better fixation of the prosthesis in a frail and dilated valve ring.

The postoperative course was marked by nonregression of the atrioventricular block necessitating a definitive pacemaker implantation and a bronchial infection treated with amoxicillin. The final echocardiogram showed good valvular performance in both the aortic and pulmonary positions with no regurgitation.

The patient was discharged 21 days after the second intervention. The 6-month follow-up was uneventful (mean pulmonary gradient $=3 \mathrm{~mm} \mathrm{Hg}$, a mild paravalvular leakage).

\section{DISCUSSION}

Pulmonary valve replacement indications are infective endocarditis on the right ventricle and the previously treated congenital cardiac malformation. ${ }^{4}$ Even if these patients are commonly frail, frequently require reoperation, and have poor right ventricle function, the percutaneous replacement of the pulmonary valve as described by Bonhoeffer and colleagues ${ }^{4}$ in 2000 is not the best treatment because of the infection or dilated annulus. In these cases, a sutureless valve is a good alternative to surgical bioprosthesis or other valved grafts because they offer an easy deployment and good implantation support for a future percutaneous valve implantation in case of structural valve deterioration. Moreover, a previously implanted aortic valve is not a contraindication for a sutureless pulmonary valve implantation, as proved in this case.

The Edwards INTUITY sutureless valve was more suitable for the pulmonary position than other sutureless valves because of the larger infravalvular stent, fitting perfectly in the right ventricle outflow tract.

\section{CONCLUSIONS}

This case report proves the safety and the ease of implantation of the Edwards INTUITY sutureless valve in the pulmonary position. We suggest a simple modification of the recommended implantation technique to prevent any valve distortion in the pulmonary annulus.

\section{References}

1. Kocher AA, Laufer G, Haverich A, Shrestha M, Walther T, Misfeld M, et al One-year outcomes of the surgical treatment of aortic stenosis with a next generation surgical aortic valve (TRITON) trial: a prospective multicenter study of rapid-deployment aortic valve replacement with the EDWARDS INTUITY Valve System. J Thorac Cardiovasc Surg. 2013;145:110-6.

2. Pollari F, Santarpino G, Dell'Aquila AM, Gazdag L, Alnahas H, Vogt F, et al Better short-term outcome by using sutureless valves: a propensity-matched score analysis. Ann Thorac Surg. 2014;98:611-7.

3. Kogon BE, Rodby KA, Kirshbom PM, Kanter KR, Lyle T, McConnell M, et al Adult congenital pulmonary valve replacement: a simple, effective, and reproducible technique. Congenit Heart Dis. 2007;2:3141-8.

4. Bonhoeffer P, Boudjemline Y, Saliba Z, Merckx J, Aggoun Y, Bonnet D, et al Percutaneous replacement of pulmonary valve in a right-ventricle to pulmonary prosthetic conduit with valve dysfunction. Lancet. 2000;356:1403-5.

\title{
EDITORIAL COMMENTARY
}

\section{Pulmonary valve replacement: A sutureless, surgical alternative?}

\author{
Harold M. Burkhart, MD
}

\footnotetext{
From the Division of Cardiovascular and Thoracic Surgery, University of Oklahoma Health Sciences Center, Oklahoma City, Okla.

Disclosures: Author has nothing to disclose with regard to commercial support.

Received for publication May 25, 2015; accepted for publication June 3, 2015.

Address for reprints: Harold M. Burkhart, MD, Division of Cardiovascular and

Thoracic Surgery, University of Oklahoma Health Sciences Center, P.O. Box 26901, WP-2230, Oklahoma City, OK 73105 (E-mail: Harold-burkhart@ouhsc. edu).

J Thorac Cardiovasc Surg 2015;150:e27-8

$0022-5223 / \$ 36.00$

Copyright (c) 2015 by The American Association for Thoracic Surgery

http://dx.doi.org/10.1016/j.jtcvs.2015.06.005
}

See related article on pages e26-7.

Right ventricular outflow tract pathology necessitating pulmonary valve replacement (PVR) for pulmonary valve stenosis or regurgitation is common. Many patients born with pulmonary valve stenosis or multilevel right ventricular outflow tract obstruction require intervention early in life. Whether percutaneous balloon valvuloplasty or surgical 